\title{
Visualize and Semantic Structure in Web Navigate Communication
}

\author{
Chyi-Wen Hwang
}

\begin{abstract}
When facing the "overabundant" of semantic web information, in this paper, the researcher proposes the hierarchical classification and visualizing RIA (Rich Internet Application) navigation system: Concept Map (CM) + Semantic Structure (SS) + the Knowledge on Demand (KOD) service. The aim of the Multimedia processing and empirical applications testing, was to investigating the utility and usability of this visualizing navigation strategy in web communication design, into whether it enables the user to retrieve and construct their personal knowledge or not.

Furthermore, based on the segment markets theory in the Marketing model, to propose a User Interface (UI) classification strategy and formulate a set of hypermedia design principles for further UI strategy \& e-learning resources in semantic web communication.

These research findings: 1) Irrespective of whether the simple declarative knowledge or the complex declarative knowledge model is used, the " $\mathrm{CM}+\mathrm{SS}+\mathrm{KOD}$ navigation system" has a better cognition effect than the "Non CM + SS + KOD navigation system". However, for the "No web design experience user", the navigation system does not have an obvious cognition effect. 2) The essential of classification in semantic web communication design: Different groups of user have a diversity of preference needs and different cognitive styles in the CM + SS + KOD navigation system.
\end{abstract}

Index Terms-Visualizing navigation, cognition navigation, multimedia information web communication design, concept map (CM), semantic structure (SS), knowledge on demand (KOD).

\section{INTRODUCTION}

This research is based on the Information Architecture design in Human Computer Interface (HCI) theory; and the Interactive; Sensorial design in User Interface (UI) theory, to explore the utility and usability of the $\mathrm{CM}+\mathrm{SS}+\mathrm{KOD}$ navigation system in the adaptive Web learning environment. Moreover, in the adoption of Knowledge Space Theory, Dietrich Albert (1997) [1] and Michael D. (2010) [2] points out: the knowledge space provides a formal model for representing students' knowledge and describing the structure of domain knowledge.

In this researcher's opinion, the Concept Map (CM); Semantic Structure (SS) and Knowledge on Demand (KOD) navigation system, integrated the multimedia metadata with a self-navigating format. This adaptive navigation method not only enhances the information communication process, but also fosters the user's cognition construction.

Manuscript received September 16, 2014; revised November 23, 2014.

Chyi-Wen Hwang is with Hsiuping University of Science and Technology, Taiwan, R.O.C (e-mail: welisfit@gmail.com).

\section{II. $\mathrm{CM}+\mathrm{SS}+\mathrm{KOD}$ NAVIGATION SYSTEM AND KNOWLEDGE (COGNITION) CONSTRUCTION}

This $\mathrm{CM}+\mathrm{SS}+\mathrm{KOD}$ navigation system consists of three fundamental parts: "visual concept perception", "hierarchical structure representation", "knowledge organization and adaptive memory".

Jonassen, Beissner \& Yacci, (1993) [3] point out that "Structural knowledge" theory, can be used to present the relationships of knowledge content in a spatial way; with a different method to express the knowledge structure, the different types of organizing techniques, can promote the different cognition processes.

TABLE I: BEISSNER, JONASSEN AND YACCI (1993): COGNITION PROCESS

\begin{tabular}{|c|c|c|c|c|}
\hline \multicolumn{2}{|c|}{ Method } & $\begin{array}{c}\text { Cognition } \\
\text { process }\end{array}$ & $\begin{array}{c}\text { Cognition } \\
\text { effect }\end{array}$ & $\begin{array}{c}\text { Cognition } \\
\text { performance }\end{array}$ \\
\hline Hierarchical & $\begin{array}{c}\text { Semantic } \\
\text { map }\end{array}$ & $\begin{array}{c}\text { Analysis } \\
\text { Organization } \\
\text { Classification } \\
\text { Elaboration } \\
\text { Interpretation }\end{array}$ & $\begin{array}{c}\text { Recall } \\
\text { Transfer }\end{array}$ & $\begin{array}{c}\text { Memory } \\
\text { Exercise }\end{array}$ \\
\hline $\begin{array}{c}\text { Non- } \\
\text { hierarchical }\end{array}$ & $\begin{array}{c}\text { Concept } \\
\text { Maps }\end{array}$ & $\begin{array}{c}\text { Integration: } \\
\text { Correlation } \\
\text { Classification } \\
\text { Establishment } \\
\text { metaphor }\end{array}$ & Deduction & Searching \\
\hline
\end{tabular}

\section{RETRIEVABLE AND REUSABLE SyStEM}

The visualized $\mathrm{CM}+\mathrm{SS}+\mathrm{KOD}$ navigation is one type of knowledge navigation system, for organizing and representing knowledge with the semantic content. It is related to multi-modal information, like the Hypermedia Streaming, VOD, MOD technology... etc. and can let the user chooses their options (knowledge) from the "popularized" to the "specialized", to reduce the searching procedures and repeat the cognition memory.

The CM + SS + KOD navigation system with adaptive \& re-usable characteristics can increase the efficiency and effectiveness of query routing during the different metadata contents, and provide convenience to the user making their personal learning during the applications processes easier.

This empirical test model of the "CM + SS + KOD navigation system" can be divided into four parts of Layers: "Multimedia objects Layer"; "Subject and specimen multimedia archives Layer"; "Knowledge elements Layer" and "Classified browsing construction Layer".

Moreover, the information metadata construction and navigation process in this system is starting from "Data collection \& classification" -- "Digital and visual processing" -- "Build up the Object Databank" -- "Data Combination and XML Translator" -- "Provide the Index 
Search; Full Text Search; Image Search; Hyper Link" -"Finally present on the Browser".

\section{Research METHODOLOGY}

Consult with H.F. Lin. (2007) [4] A stage model of knowledge management theory. The methodology in this research selected the Taiwan National Digital Archive Program: "The Digital Museum of Nature \& Culture" web site: http://digimuse.nmns.edu.tw/index.jsp and aims at the Botany category for this empirical test sample (the test contents included simple declarative knowledge and the some complex terminology declarative knowledge). Firstly, the researcher designed a "No navigation system" edition to compare with the web edition of "Have CM + SS + KOD navigation system", and then explored what kinds of design strategies that can motivate the user's cognitive comprehension; recall ability and learning retention. The researcher used random sampling and random clusters to choose 100 testees from the general public (for each experimental edition respectively), the testee's ages ranged from 18 to 65 years old.

Secondly, as Duffy, Lowyck \& Jonassen (1993) [5] expressed: The different knowledge categories should have different knowledge structures; design methods and learning strategies, and refer to Pataraia, N: An ego-centric network theory (2014) [6]. The researcher designed a questionnaire: "CM + SS + KOD in Hypermedia Web Site navigation Questionnaire", and according to the empirical test results to divided the testers into three groups: "Novice"; " Experienced"; "Expert".

This rating standard is adopted from Novak \& Gowin (1984) [7], [8] and is used to analyze the different user's ability to construct the correct relationships and knowledge structure of Concept Maps \& Semantic Structures. (As in the Fig. 3, Fig. 4 below) If the user makes a proposition $=1$ point; makes a Hierarchy $=5$ points; makes a Cross-link = 10 points; makes an Example $=1$ point. If the total score $<10=$ the testee belongs to the "Novice" group; if the total score $>=10$ and $<50=$ the testee belongs to the "Experienced" group; if the total score $>=50=$ the testee belongs to the "Expert" group.
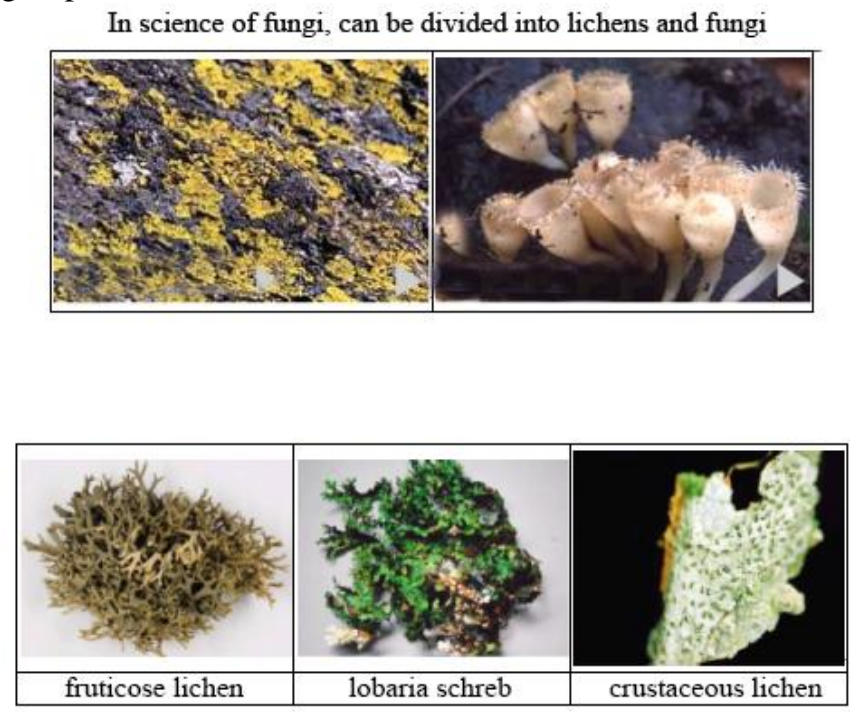

Fig. 1. No CM + SS + KOD navigation system.

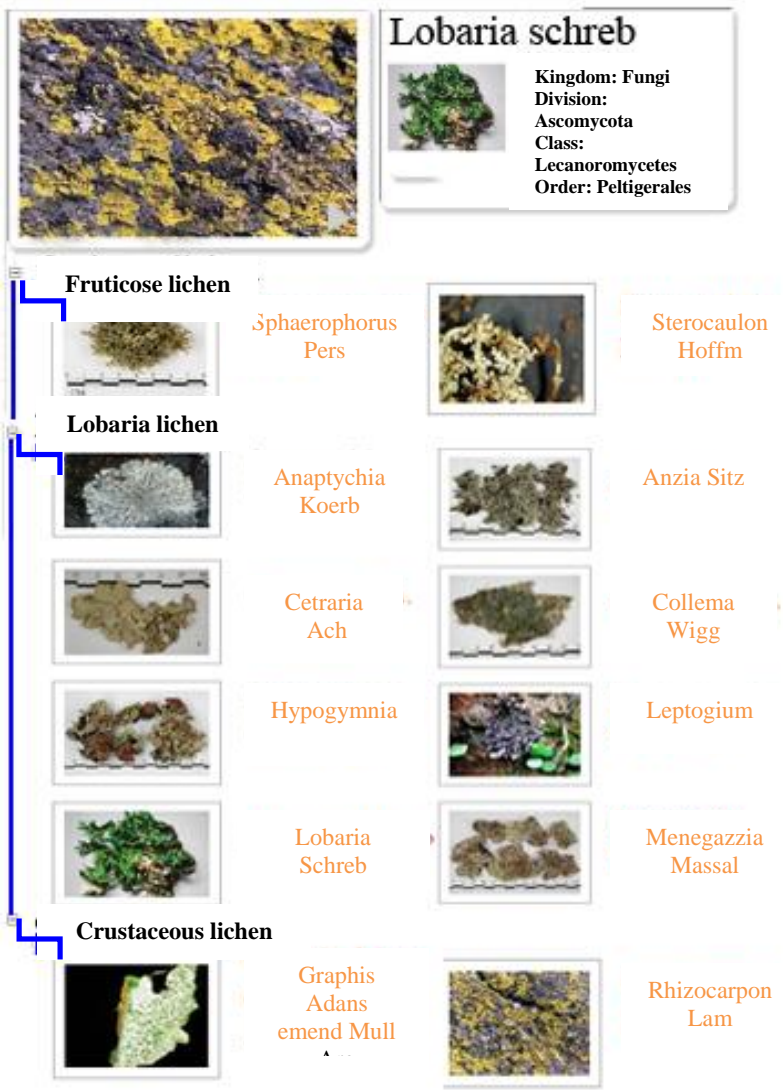

Fig. 2. Have CM + SS + KOD navigation system.

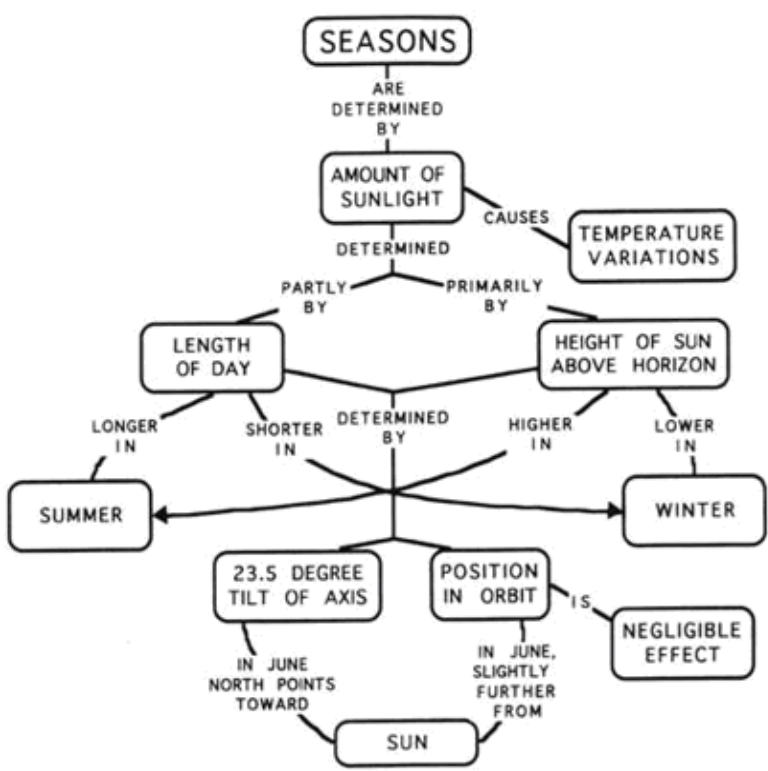

Fig. 3. The complete diagram of CM.

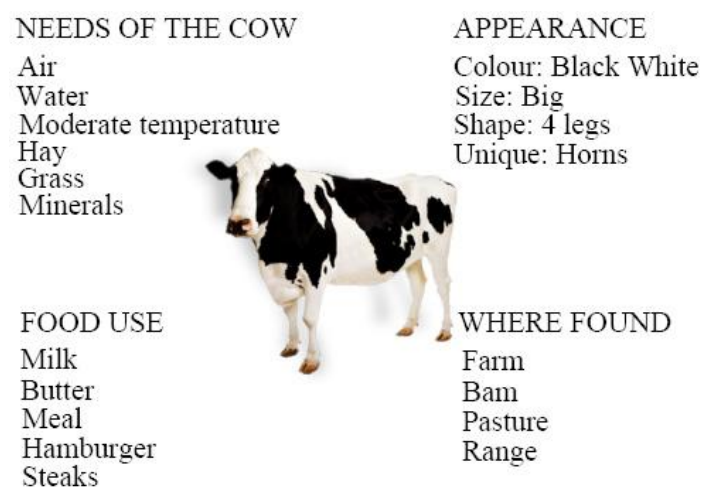

Fig. 4. The sample question of SS. 


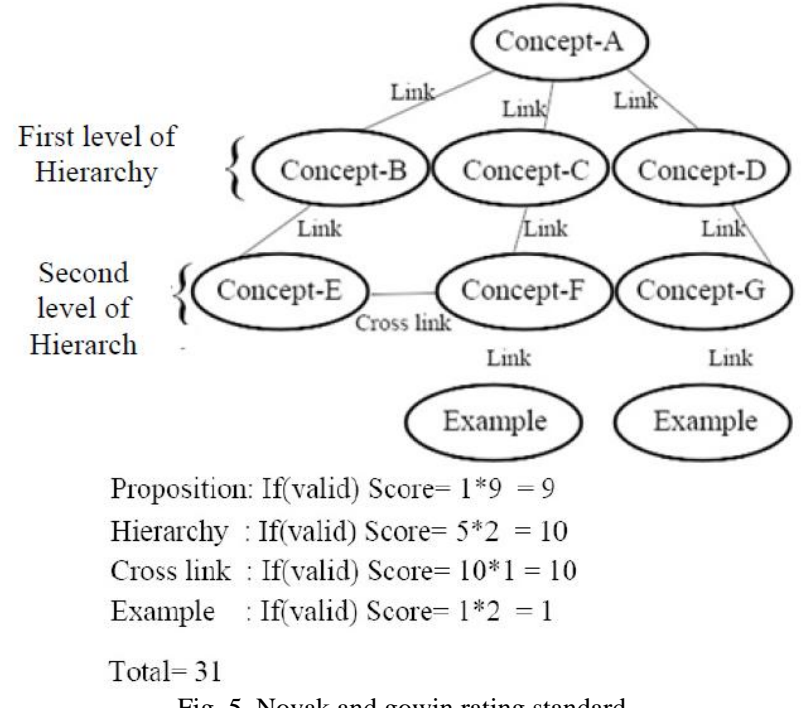

Fig. 5. Novak and gowin rating standard.

\section{RESEARCH FINDING (1): DoES THE USER NEED A NAVIGATION SYSTEM?}

The data was analyzed comparing the pre-test \& post-test results to assess the validity of the "No navigation system" against the "Have CM + SS + KOD navigation system" and using SPSS to analyze the Paired-Samples; T-Test (testretest reliability).

In the "No navigation system" edition, the validity of Correlation $=0.906, P=0.591>0.05$; in the other case, the "Have CM + SS + KOD navigation system", the validity of Correlation $=0.875, P=0.591>0.05$. Cronbach's Alpha $=$ 0.890 .

Comparing the results from this two editions indicated that: Irrespective of whether the "Have CM + SS + KOD navigation system" or the "No navigation system" was used by the "No web design experience groups" there was no obvious difference and have no urgent need than the "Have learned Web Site Design Group".

Comparing the pre-test result from six months before, 24 testees of the "No web design experience groups", subsequently took the professional computer curriculum and operation skill training. The post-test result of these in the "Have CM + SS + KOD navigation system" showed a significant improvement.

\section{RESEARCH FINDING (2): DIFFERENT USERS NEEDS AND INDIVIDUALIZED CLASSIFICATION DESIGN}

Considering the different users have different prior knowledge, intelligence factor and cognitive style, the researcher designed a "CM + SS + KOD in Hypermedia Web Site navigation Questionnaire", to test the individuals different needs. Analysis using SPSS, into the validity of this questionnaire resulted in a Cronbach's Alpha value of: 0.7074."

Moreover, using ANOVA to analyze the question: "Do you agree the amplitude of information will cause the user "Cognition overload?" With another variable: "Do you think the $\mathrm{CM}+\mathrm{SS}+\mathrm{KOD}$ navigation system based on the hypermedia navigation service will enhance the users cognition and their learning?) (The Mean Square $=1.343 ; F$
$=3.661$; Pearson Correlation $=0.264 ; P<0.05^{*}$ ). And "Do you think the hypermedia KOD navigation service, is suitable for personal learning and knowledge management?" (The Mean Square $=1.852 ; F=5.362$; Pearson Correlation $=0.238 ; P<0.01 * *)$.

$79 \%$ of all the testees "Strongly Agree" and "Agree": the Concept Map \& Semantic Structure navigation based on the hypermedia service, will enhance the user's Web usability \& cognition in their learning. And $83 \%$ of all the testees also "Strongly Agree" and "Agree" that the hypermedia KOD service, is suitable for personal learning and knowledge management".

From the questionnaire test and in-depth interview result. The three-groups of users have diverse needs with the CM + $\mathrm{SS}+\mathrm{KOD}$ navigation system, the researcher list the result as below:

\section{A. How Many Semantics Navigation Sub-Links Do the Interviewee Favor [9]?}

Expert groups: 6 10 sub-links; Experienced groups: 5 10 sub-links; Novice groups: 6 10 sub-links.

From the testee feedback: Too many semantic sub-links of information (data), will defer the time for the user to search and filter the information.

\section{B. The Different Adaptive Navigation Preference in Different-Groups is}

\section{1) Expert groups}

Members of this group with a high level of prior knowledge in $\mathrm{CM}+\mathrm{SS}+\mathrm{KOD}$, and a greater ability for comprehension; are able to create the mind-structure by themselves; and there is no need to provide additional navigation support for them. The most suitable way is provide "Direct guidance" and flexible paths; e.g. Search engines and Information on Demand (IOD) navigation services. Moreover, the expert group will not blindly use the navigation system, it just depends on the topic or target (if he/she has a clear prior knowledge or not), they also consider whether to uses $\mathrm{CM}+\mathrm{SS}+\mathrm{KOD}$ navigation system by this way.

\section{2) "Experienced" and "novice" groups"}

Typically these groups have a low level of prior knowledge in $\mathrm{CM}+\mathrm{SS}+\mathrm{KOD}$, and limited comprehension ability about the content, also lack the domain knowledge and concept structures. The suitable additional navigation support includes providing the visual cues---with adaptive navigation structured paths, to help the novice users integrate their knowledge, e.g. "Adaptive sorting of links" and "The adaptation of the guiding map"; "Visualized hierarchical maps".

\section{User Interface Design}

\section{1) "Expert" groups}

Prefer the "Direct guidance" of "Intuitive observation" design; and regard for the "Integrity"; "Utility"; "Usability" and" retrieve" navigation function. Ex: IOD.

\section{2) "Experienced groups"}

Prefer the "Simple" and "Explicit" spatial knowledge design patterns with the "Visualized knowledge scaffold" and "Hierarchical structure path". 
Should be provided with the "Adaptive navigation" service, which can help to find the data clearly \& organize information quickly. But do not like the mechanism with numerous and disorderly semantic-sub-links.

\section{3) "Novice groups"}

Prefer more" Simple", "Convenient" and the "Visual" interface design. Moreover, provide the "Adaptive navigation" with the structured catalogue and key-word index searching.

\section{CONCLUSIONS AND SUGGESTION}

$\mathrm{CM}+\mathrm{SS}+\mathrm{KOD}$ can facilitate the buildup of standardization; also it may take advantage of understanding the related or deeper knowledge structure and communication content. This self-adaptive \& objectoriented systems in particular enable the user to easily retrieve the hypermedia metadata and re-use different complex or interesting content.

This researchers' conclusions are: the CM + SS + KOD navigation system has the superior features in that it; 1) Extends the characteristic of hypertext; 2) Provides quality of service, adaptive to demand; 3) Overviews the web "shape" of the whole structure; [10] 4) Allows cognitive structure navigation with meaningful learning [11], [12]; 5) Contributes to the cognition memory (based on the UI interactive design and sensorial design); 6) Allows for nonlinearity, flexibility and interactive construction in visual communication; 7) Provide the on-demand retrievable \& reusable services[13], [14].

Finally, based on the characteristics of the $\mathrm{CM}+\mathrm{SS}+$ KOD navigation system and research findings, some of the suggestions can be use to help the semantic Web content designer and other researchers in the future, such as:

1) Avoid "amplitude"; "scattered" and "aimless" semantic information design

2) "Direct guidance"-- simple \& intuitive is the primary principle;

3) Provide visualizing navigation --- Integrated with multimedia metadata; to promote information navigation, recording and retention to the related information context;

4) Provide the classification of semantic UI design with personalized searching and interactive data mining;

5) Based on the user-centered methods, design personalized channel \& personal marketing services, ex: personal VOD \& AOD navigation podcasting. 8). Using the AJAX [15] (Asynchronous JavaScript and $\mathrm{XML}$ ) and Flash Lite techniques to extend the multimedia video \& audio RIA navigation service [16].

\section{ACKNOWLEDGMENT}

The authors wish to thank Hsiuping University of Science and Technology, Taiwan, R.O.C. This work was supported in part by a grant from Hsiuping University of Science and Technology, Taiwan, R.O.C.

\section{REFERENCES}

[1] D. Albert and C. Hockemeyer, "Adaptive and dynamic hypertext tutoring systems based on knowledge space theory," in Proc. the Frontiers in Artificial Intelligence and Applications, vol. 39, 1997, p. 1 .

[2] M. D. K. Rust and D. Albert, "Micro-adaptivity: Protecting immersion in didactically adaptive digital educational games," $J$. Comp. Assisted Learning, vol. 26, no. 2, pp. 95-105, 2010.

[3] K. Beissner, D. H. Jonassen, and M. Yacci, "Using and selecting graphic techniques to acquire structural knowledge," Document Reproduction Service, vol. 40, 1993.

[4] H. F. Lin, "A stage model of knowledge management: an empirical investigation of process and effectiveness," Journal of Information Science, vol. 336, pp. 643-659, 2007.

[5] T. M. Duffy, J. Lowyck, and D. H. Jonassen, "Designing environment for constructive learning," NATO ASI Series, Heidelberg: Springer-Verlag, vol. 105, 1993.

[6] N. Pataraia, A. Margaryan, I. Falconer, A. Littlejohn, and J. Flaconer, "Discovering academics' key learning connections: An ego-centric network approach to analyzing learning about teaching," Journal of Workplace Learning, vol. 26, no. 1, pp. 56-72, 2014.

[7] La Grille d'évaluation de Novak et Gowin, Learning How to Learn, Cambridge: Cambridge University Press, 1984, pp. 36-37.

[8] A. J. Cañas, G. Hill, R. Carff, N. Suri, J. Lott, T. Eskridge et al., "Cmap tools: A knowledge modeling and sharing environment," concept maps: Theory, methodology, technology," in Proc. the First International Conference on Concept Mapping, 2004, pp. 125-133.

[9] T. Burger, "The need for formalizing media semantics in the games and entertainment industry," Journal of Universal Computer Science, vol. 14 , no. 10 , pp. 1775-1791, 2008.

[10] C. C. Chiou, "The effect of concept mapping on students' learning achievements and interests," Innovations in Education and Teaching International, vol. 45, no. 4, pp. 375-387, 2008.

[11] A. Margaryan, A. Littlejohn, and G. Vojt, "Are digital natives a myth or reality? Students' use of technologies for learning," Computer and Education, vol. 56, no. 2, pp. 429-440, 2011

[12] S. C. Y. Yuen, G. Yaoyuneyong, and P. Yuen, "Perceptions, interest, and use: Teachers and web 2.0 tools in education," International Journal of Technology in Teaching and Learning, vol. 7, no. 2, pp. 109-123, 2011.

[13] T. T. Do, K. A. Hua, and M. A. Tantaoui, "Providing fault tolerant video-on-demand streaming in peer-to-peer environment," in Proc. the IEEE International Conference on Communications (ICC), Paris, France, 2004.

[14] B. Krithikaivasan, Y. Zeng, K. Deka, and D. Medhi, "Arch-based traffic forecasting and dynamic bandwidth provisioning for periodically measured nonstationary traffic," IEEE/ACM Transactions on Networking, vol. 15, no. 3, pp. 683-696, 2007.

[15] B. Salva, "Patrice lauren and ccedil, ot: Automatic ajax application testing," in Proc. the 4th International Conference on Internet and Web Applications and Services, 2009, pp. 229-234.

[16] S. Melia, J. Gomez, S. Perez, and O. Diaz, "A model-driven development for GWT-based rich internet applications with OOH4RIA," in Proc. the ICWE '08. Eighth Conf. on Web Engineering, 2008, pp. 13-23.

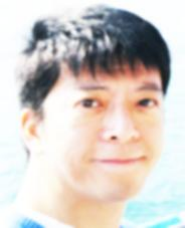

Chyi-Wen Hwang is from Taiwan, he received his MA degree in multimedia design from De Montfort University, U.K and he is a lecturer at Hsiuping University of Science and Technology, Taiwan. R.O.C. $\mathrm{He}$ has published papers in many international journals. 